\title{
A qualitative description of soil parameters variation due to a prescribed fire in Portuguese northwestern forests using Fuzzy Boolean Nets - The case study of Cabreira mountain
}

\author{
Ana C. Meira Castro, Joao Paulo Carvalho, Joao Paulo Meixedo
}

\begin{abstract}

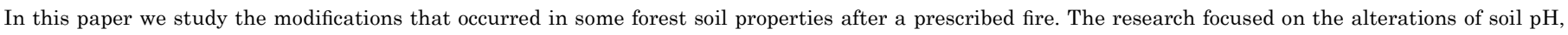

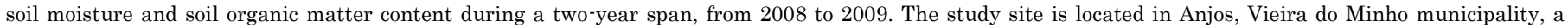

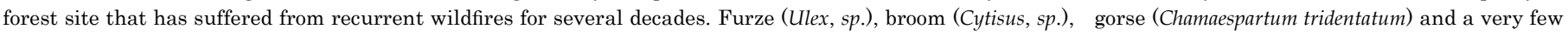

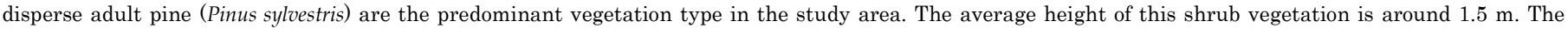
prescribed fire was conducted by the National Forestry Authority (AFN) in November 2008.

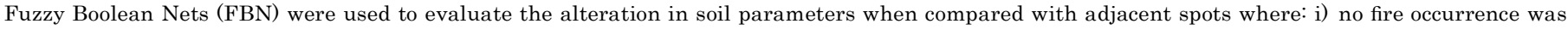

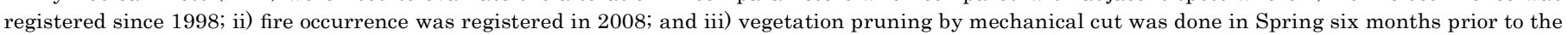
prescribed fire event.

Results suggest that in the particular case of the studied site, Anjos, the observed soil properties alterations cannot be related with the prescribed fire.
\end{abstract}

\section{Keywords}

Fuzzy Boolean Nets, Controlled fire, Forest soil, Soil parameters variation, Cabreira Mountain (Portugal)

\section{Introduction}

Mediterranean forest wildfires are a natural phenomenon that have occurred for millennia. These wildfires contributed to shape the forests landscape and vegetation. The southern European wildfire landscapes can be considered different from those of the rest of Europe due to the fact that the fire regimen is not only influenced by the climate and meteorological conditions, but also by human activity (Pausas and Vallejo, 1999). In fact, due to industrialization and generalized rural exodus, fields were abandoned, and this local scale land-use change promoted the availability of a flammable cover that, in combination with favorable atmospheric conditions, drove an increase in the number of natural wildfires burnt area (Pausas et al., 2008). In Portugal, natural forest wildfire events are more prone to occur during the average Mediterranean Summer season, characterized by high temperatures and low relative air humidity. Summer comes after a period of rain and lower temperatures, lasting from October to May, that support the availability of fuel mass (Carvalho et al., 2008; Trigo et al., 2006). These meteorological conditions, in conjunction with strong winds, increase remarkably the tendency of forest wildfires to occur (Viegas, 2006). Though fire activity in Portugal presents high spatial and temporal variability for burnt area and fire occurrences, the Northern and central regions have much more severe fire seasons in terms of number of occurrences and burnt areas than the Southern regions due to nonmeteorological factors that show denser patterns of vegetation and human occupation in the North (Durão et al., 2010).

It is known that wildfire events are responsible for expressive impacts on water-soil-plant-fauna ecosystems and thus significant socio-economical disturbances. Several studies suggest that each ecosystem shows a particular response to fire: some have a high capability to develop mechanisms that turns them more and more resilient to fire, as for example shrub lands and oak forests; others are more fire-sensitive. However, when in the presence of high fire severity, both experience soil loss, erosion and vegetation recovery (Bitner et al., 2001; Certini, 2005; DeBano, 2000; González-Pérez et al., 2004; Neary et al., 1999; Neary et al., 2008; Shakesby and Doerr, 2006). Conscious about this, several wildfires impact studies have been done at Portuguese local-scale and reveal, on top of the loss of human lives and human suffering (Viegas, 2006), changes in air quality (Miranda et al., 1994), changes in soil properties and hydrology (Coelho et al., 2004; Ferreira et al., 2000; Moreira et al., 2003; Silva et al., 2006), and changes in soil properties and biota (Catry et al., 2010; Shakesby et al., 1996) in accordance with studies carried out 
in several European Mediterranean ecosystems (Arianoutsou, 2006; Cerdà and Doerr, 2005; Gimeno-Garcia, et al., 2000; Kutiel and Inbar, 1993; Mayor et al., 2007; Shakesby, 2011; Zozaya et al., 2011). These studies state that, when considering a climate-weather scenario, there is a strict relation between the specificity of the ecosystem and the resulting fire impact.

Prescribed fire practice for biota control and for reduction of forest fuel mass availability, and therefore to promote the reduction of wildfire occurrence and a shorter fire suppression effort, is a common tool used in forest management. In Portugal, this burning technique is legislated (AFN, 2006; IPQ, 2009; MADRP, 2007; PCM, 2006; RCM, 2006). However, as referred to above, the impact in ecosystem recovery after burning is highly dependent on biota community composition before the burn, on the intensity and pattern of the fire, on weather conditions after the burn, and on the geomorphologic and geologic variability of the affected site. Therefore, conclusions regarding the effects of prescribed fire on a specific site should not be generalized.

The number of scientific works concerning the prescribed fire impact in soil system in Portugal, particularly in Northwestern forest soils, is very small when compared to the scientific research that has been carried on the topic in the Mediterranean region. However, all reveal that temporal and spatial scale variations can influence the results of the forest soil dynamics. Some illustrate that prescribed fire practices are adequate since they allow soil and biota to recover, but others prove that prescribed fires can also cause abrupt and nonrecoverable environmental changes (Botelho, 2000; Botelho et al., 1998; Meira-Castro et al., 2011; Moreira et al., 2003; Úbeda, et al., 2005; Vega et al., 2005). In this context, where local-scale impact in the northwestern Portuguese forests is still an open issue, the Portuguese National Authorities encourage the continuing acquisition of scientific knowledge.

This paper focuses on the assessment of the adequacy of properly timed controlled fire technique usage in stony soil area located in Anjos, Cabreira Mountain, a Portuguese northwestern forest soil where recurrent wildfires persist and fuel mass reduction must be done. Although Cabreira Mountain has been the subject of various studies by several researchers that emphasized remarkable soil loss year after year (Bento-Gonçalves, 2006; Campos, 2004; Devi-Vareta, 1993; Ferreira-Leite et al., 2011), none of the studies focused on soil first layers properties. Considering this, this work presumes to be one step forward for decision makers to effectively say if prescribed fire, carried out in this specific type of area, can be considered to be an efficient practice to reduce forest fuel mass availability and for vegetation management or if, even done under strict operational conditions, the sustainability of this action is compromised. A Fuzzy Boolean nets methodology is used to characterize the alteration of soil $\mathrm{pH}$, soil moisture and soil organic matter content values. The burning was carried out by AFN, the National Forestry Authority, under firmly cautious operational rules and the soil monitoring was conducted during a twenty-one-month span.

\section{Materials and methods}

\subsection{The study site}

Anjos region is located in the Cabreira Mountain, in the municipality of Vieira do Minho in northwestern Portugal (Fig. 1). The altitude of the studied site varied between 700 and $1000 \mathrm{~m}$. Vieira do Minho municipality is dominated by wildlands ( $86 \%)$, with $12 \%$ of the area occupied by croplands. In Cabreira Mountain, shrubs species are the dominant kind of vegetation ( $50 \%$ of the total area) due to a negative trend in population growth since 1991, marked by low birth rates and aging population, agricultural abandonment and lack of livestock management (Ferreira-Leite et al., 2011). Cabreira mountain has suffered from annual recurrent wildfires for several decades (DeviVareta, 1993). In Anjos, most of shrub vegetation is about $1.5 \mathrm{~m}$ tall and the dominant species are furze (Ulex, sp.), broom (Cytisus, sp.), gorse (Chamaespartum tridentatum) and very few (almost none) disperse adult pine (Pinus sylvestris). This vegetation appears in places where the original forest is degraded, where damp conditions are low, and where soil is relatively shallow. According to the Soil Map of the Entre-o-Douro-e-Minho region (Agroconsultores and Geometral, 1995), which encompasses the study site, the dominant soil units based on the Revised Legend of the Soil Map of the World (FAO, 1988) are Umbric Leptosols, Umbric Regosols and Humic Cambisols. In fact, Anjos is located in a contact zone between two-mica coarsegrained porphyritic granite and a biotite with plagioclase granite and the sampling sites are located in a spot dominated by quartzphyllite with quartz veins. The bedrock is partially altered and covered by slightly thick humus, which maintains low undergrowth vegetation (Ribeiro et al., 2000).

Considering atmospherical tendencies, one of the most remarkable features of the Cabreira Mountain is the high level of precipitation. Guilhofrei meteorological station, located at $550 \mathrm{~m}$ altitude and less than one kilometer distance from Anjos, reveals typically high values of annual average precipitation (about $2705.7 \mathrm{~mm}$ ) and a prominent number of rainy days (about 134). This predisposition in Anjos is reinforced by the records in the second nearest official meteorological station in Zebral and Salamonde (Ferreira-Leite et al., 2011).

The study site has a significant slope (near $30 \%$ ) and it is possible to observe a relevant ongoing pasture activity.

\subsection{Methodology}

The National Forestry Authority provided a perimetrally guided prescribed fire in November 2008 with the goal of burning 54.6 ha (Fig. 2). The vegetation moisture, both superficial and dead floor, was considered in a range from low humic to dry. The meteorological data were considered to be reasonable for the prescribed burning action by the coordinator of this action: at the beginning of the fire the recorded air temperature was $9.5^{\circ} \mathrm{C}$, the relative humidity $74 \%$, the wind velocity $9.1 \mathrm{~km} / \mathrm{h}$ at $2 \mathrm{~m}$ above ground, direction NW, and the weather was scattered clouds (10-50\% covering). The burning plan was followed $100 \%$ with no tree-top consumed (Fig. 3). The immediate effects were very satisfactory, as a $70 \%$ fuel mass reduction was achieved (Vivas, 2008).

The methods used in soil sampling collection methodology were conducted according to standard procedures for forest soils (EUFIRELAB, 2006; ISO 10381-1, 2002; ISO 10381-2, 2002). The soil samples were collected in 24 randomly located points, 4 of them corresponding to control points: one located in a spot where the vegetation was pruned in May 2008; a second one located in an area that was submitted to prescribed fire in April 2008; two others where no fire or pruning occurred during a 10 year span. The sample collecting procedure was very difficult in this rugged terrain, even if it was possible to conduct it according to the procedures referred to above. The soil samples were transported to the laboratory in airtight bags clearly identifying the sampling collection point and the date of the collection procedure. The collection procedure dates were: before the prescribed forest fire; right after the prescribed fire; and 4, 7 and 21 months after the prescribed forest fire. Following, samples were prepared and submitted to analyze in a chemical analysis laboratory. Soil moisture, organic matter and $\mathrm{pH}$ were determined according to international standard methodologies, namely ISO 11464, 2006, ISO 11465, 1993 and ISO 10694, 1995. Table 1 summarizes the obtained results.

\subsection{Previous studies involving the same location}

The effect of the prescribed fire on Anjos soil moisture, organic matter and $\mathrm{pH}$ during a period of seven months has been presented previously (Ribeiro et al., 2010). Results from basic statistical analysis 


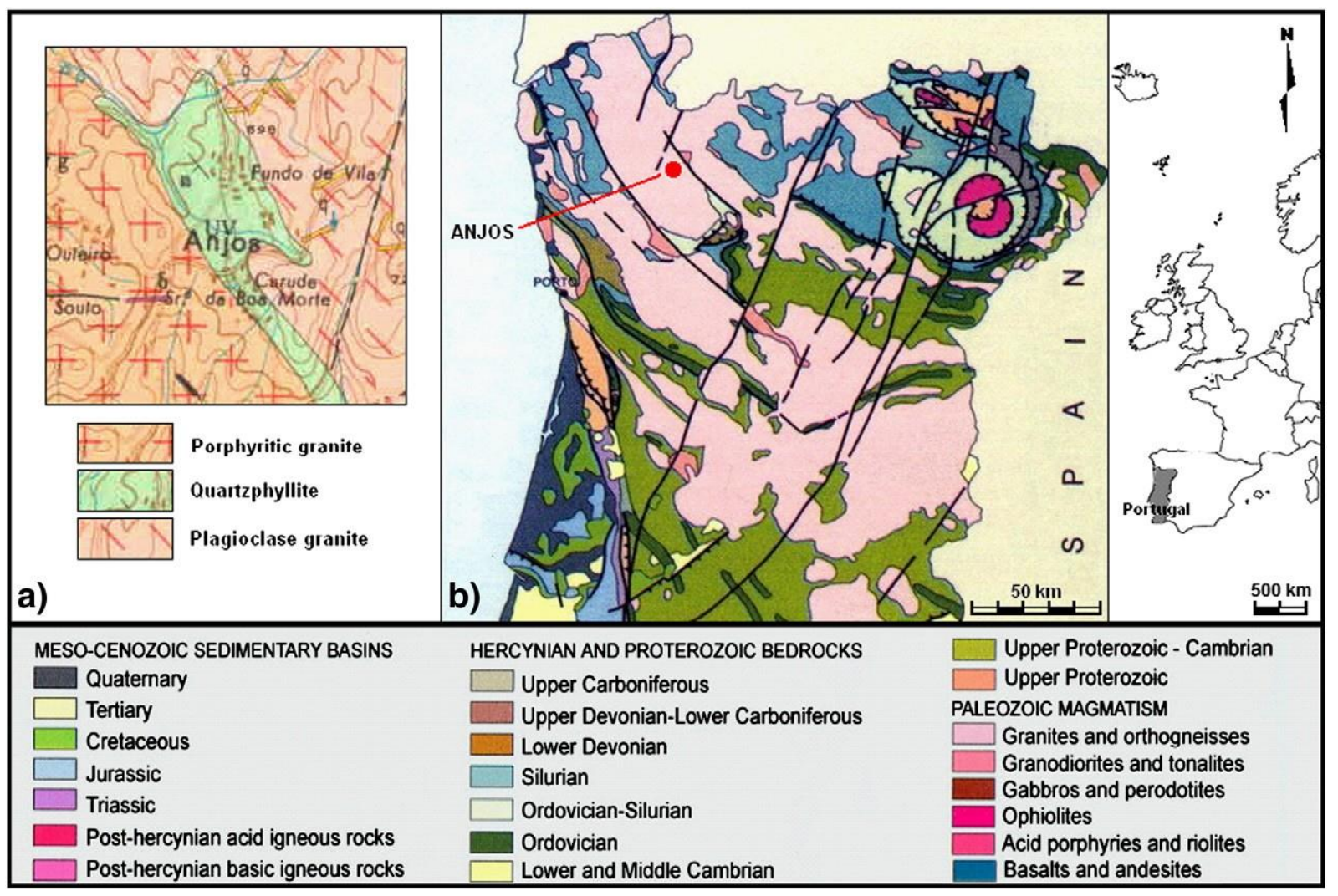

Fig. 1. a) Adaptation of Anjos's Geological Chart of Portugal, sheet 6-C (Agroconsultores and Geometral, 1995), b) Relative location of Anjos (extract of the Geological Map of Portugal).

showed that seven months after the controlled fire event: 1 - the values of soil $\mathrm{pH}$ did not change significantly; 2 - the average values of the soil organic matter decreased when compared with the initial values obtained before the prescribed fire; 3 - variations in soil moisture did not show a tendency for change.

Another study compared soil $\mathrm{pH}$, moisture and organic matter changes in Anjos with samples collected in Gramelas (municipality of Caminha, in Northwestern Portugal) under a similar intensity controlled fire scenario, vegetation and during the same six-months period (Meira-Castro et al., 2010). Gramelas is referred in the Portuguese cartographic unit as $\mathrm{Ru}$ 1.1. It has its pedological dominant units the thin umbric regosol in shale (RGul.x) and the umbric leptosol in shale (LPu.x). As the subdominant pedological units, it has the chromic cambisol humic/umbric in deposits of quartzite and/or shales (CMux.vq), and the dystrict leptosol in shale (LPd.x). According to the information available in the Portuguese soil map, this soil has the following characteristics: low capacity of cationic exchange, low degree of base saturation and low capacity of water and nutrient retention (DRAEDM, 1995; Serviços Geológicos de Portugal, 1961). The examination of the impact of the prescribed fire on these soil parameters in these two different types of soils was done by Principal Component Analysis multivariate statistics technique. Based on the gathered information, it was concluded that the prescribed fire clearly produced an impact on these soil parameters. The data analysis, considering that the two first factors explain, together, $68 \%$ of the variability in the initial data matrixes, clearly indicates that: i) all the

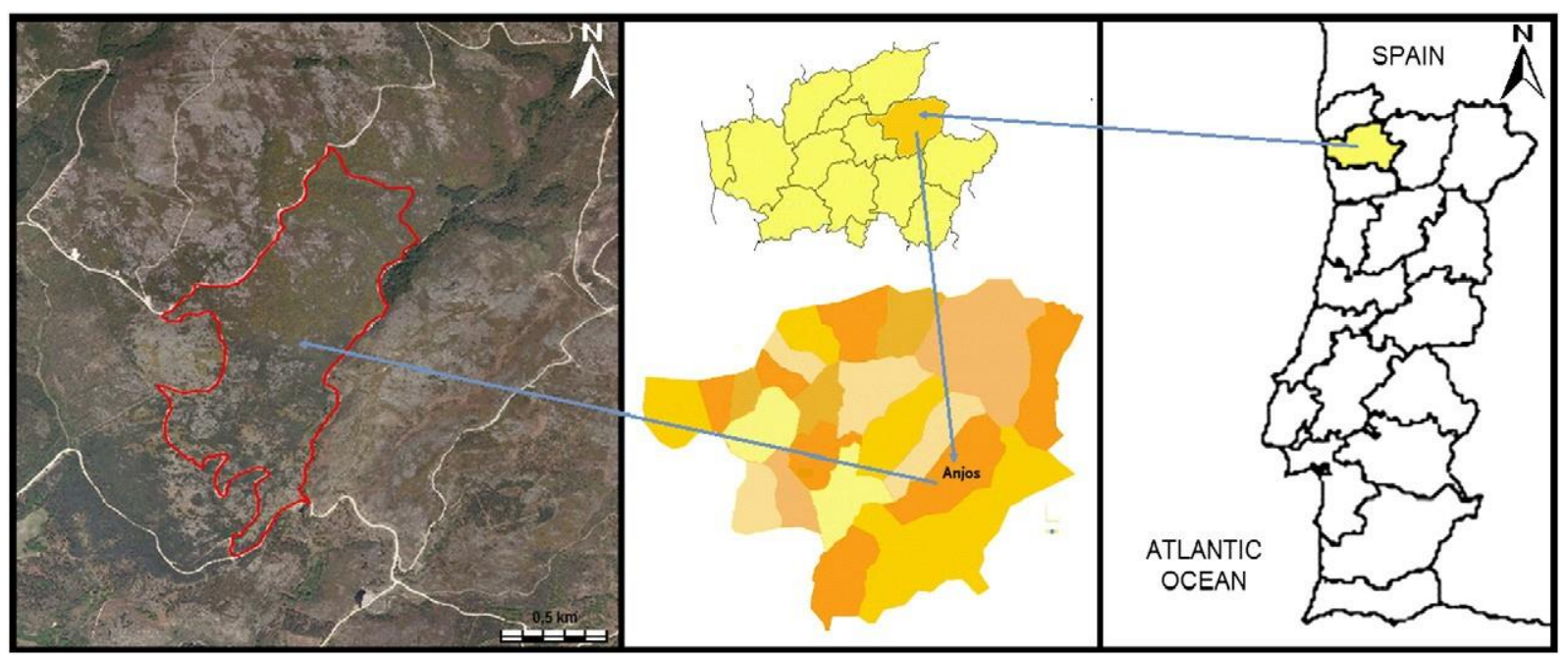

Fig. 2. Study area limitation and appearance before the prescribed fire, adapted from Vivas (2008). 


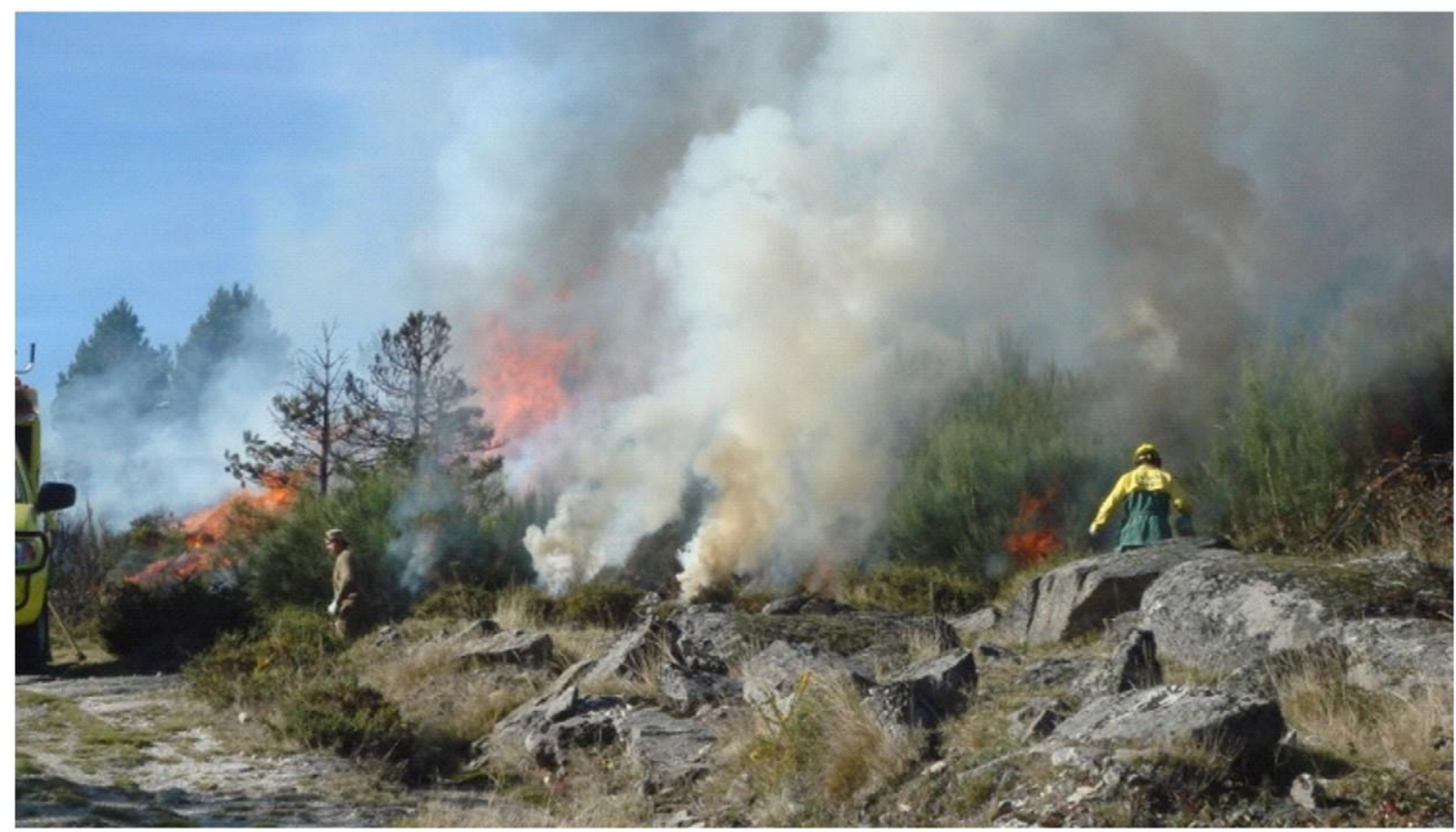

Fig. 3. Study area during prescribed fire.

parameters values (soil $\mathrm{pH}$, moisture and organic matter) are negatively correlated with organic matter values obtained immediately after the prescribed fire. However, the $\mathrm{pH}$ values are positively correlated with organic matter values 3-6 months after the prescribed fire in both sites; ii) geomorphologic and geologic differences between both sampling sites, Gramelas and Anjos, are relevant as the soil properties considered have shown different performances in time; iii) comparatively, the prescribed fire technique usage produces a lower impact in soils originated from more amended bedrock and therefore a ticker humus covering (Gramelas) than in more rocky soils with less litter covering (Anjos) as, six months after the prescribed fire occurrence, the Gramelas site was able to recover the organic matter values to levels closer to the ones that were obtained before prescribed fire, while in Anjos, that recovery was not possible to obtain.

\subsection{Using FBN and Fuzzy Rule based inference to extract information on prescribed fire effects in soil properties}

For this study, we used a similar approach to the one presented in Meira-Castro et al. (2010). This approach consists in applying Fuzzy Boolean Nets (FBN) to try to extract qualitative reasoning from the collected data. FBN's main advantage lies in its capability to deal

Table 1

Laboratory soil analysis results.

\begin{tabular}{|c|c|c|c|c|c|c|c|c|c|c|c|c|c|c|c|}
\hline \multirow[b]{2}{*}{ Sample } & \multicolumn{5}{|l|}{$\mathrm{pH}$} & \multicolumn{5}{|c|}{ Soil moisture (\%) } & \multicolumn{5}{|c|}{ Organic matter (\%) } \\
\hline & $\mathrm{pHO}$ & $\mathrm{pH} 1$ & $\mathrm{pH} 2$ & $\mathrm{pH} 3$ & $\mathrm{pH} 4$ & SM0 & SM1 & SM2 & SM3 & SM4 & Om0 & Om1 & Om2 & Om3 & Om4 \\
\hline 1 & 5.20 & 4.52 & 4.30 & 4.25 & 4.58 & 27.24 & 18.90 & 18.64 & 24.59 & 11.12 & 14.44 & 10.03 & 24.14 & 10.54 & 2.32 \\
\hline 2 & 4.74 & 4.25 & 4.47 & 3.93 & 4.48 & 29.63 & 26.74 & 19.84 & 23.85 & 5.62 & 13.03 & 11.26 & 7.99 & 14.81 & 6.84 \\
\hline 3 & 3.89 & 3.89 & 4.27 & 3.63 & 4.76 & 35.67 & 15.97 & 13.79 & 32.00 & 6.82 & 23.85 & 24.08 & 5.31 & 18.12 & 8.43 \\
\hline 4 & 4.07 & 3.67 & 4.29 & 4.11 & 4.06 & 21.38 & 18.29 & 9.48 & 25.61 & 3.56 & 23.78 & 22.61 & 13.50 & 9.32 & 10.23 \\
\hline 5 & 3.64 & 3.69 & 3.75 & 3.60 & 3.77 & 23.19 & 25.78 & 18.88 & 20.99 & 7.84 & 24.05 & 7.30 & 12.01 & 9.39 & 3.57 \\
\hline 6 & 3.73 & 3.90 & 4.46 & 4.80 & 3.84 & 22.74 & 12.79 & 18.00 & 26.09 & 9.64 & 10.24 & 17.92 & 15.02 & 14.57 & 3.02 \\
\hline 7 & 3.96 & 3.91 & 3.94 & 4.51 & 3.97 & 19.30 & 20.85 & 23.34 & 28.50 & 4.48 & 18.11 & 24.48 & 27.05 & 8.68 & 6.90 \\
\hline 8 & 4.37 & 3.74 & 4.63 & 3.83 & 4.02 & 22.89 & 21.02 & 23.94 & 17.79 & 5.62 & 9.83 & 10.63 & 13.29 & 12.17 & 5.33 \\
\hline 9 & 3.41 & 3.47 & 3.80 & 3.45 & 4.56 & 26.84 & 17.60 & 15.41 & 24.87 & 10.10 & 19.34 & 25.08 & 22.32 & 8.99 & 3.45 \\
\hline 10 & 3.93 & 3.87 & 3.87 & 3.51 & 3.98 & 22.23 & 23.47 & 10.38 & 22.84 & 8.24 & 18.43 & 15.98 & 15.12 & 11.87 & 4.24 \\
\hline 11 & 3.65 & 3.60 & 4.23 & 3.45 & 4.12 & 20.41 & 19.62 & 6.24 & 30.96 & 3.56 & 2.12 & 13.25 & 25.85 & 13.91 & 9.56 \\
\hline 12 & 3.90 & 4.19 & 4.34 & 3.99 & 4.65 & 16.54 & 16.88 & 28.06 & 32.42 & 7.56 & 5.61 & 1.22 & 7.89 & 21.27 & 4.56 \\
\hline 13 & 3.63 & 3.84 & 4.34 & 4.05 & 4.48 & 22.47 & 10.02 & 16.57 & 26.90 & 4.36 & 10.62 & 17.03 & 12.54 & 11.65 & 7.24 \\
\hline 14 & 3.66 & 4.39 & 4.32 & 4.37 & 3.98 & 22.13 & 18.74 & 20.73 & 28.01 & 7.87 & 29.83 & 8.73 & 23.79 & 11.85 & 3.59 \\
\hline 15 & 3.85 & 4.59 & 4.54 & 3.59 & 3.45 & 20.95 & 23.26 & 17.79 & 5.71 & 5.52 & 10.98 & 24.48 & 13.39 & 3.67 & 4.33 \\
\hline 16 & 3.82 & 3.77 & 4.51 & 3.72 & 4.35 & 21.74 & 22.51 & 8.37 & 20.71 & 3.21 & 15.66 & 15.51 & 15.67 & 9.48 & 11.33 \\
\hline 17 & 4.45 & 4.23 & 4.31 & 4.06 & 4.18 & 18.92 & 16.17 & 5.94 & 26.79 & 12.32 & 8.14 & 22.88 & 14.48 & 15.65 & 3.01 \\
\hline 18 & 4.40 & 3.66 & 4.08 & 3.99 & 3.68 & 12.45 & 30.80 & 16.78 & 20.41 & 5.66 & 8.43 & 16.15 & 16.07 & 12.59 & 7.23 \\
\hline 19 & 3.74 & 4.44 & 4.56 & 4.27 & 4.22 & 29.03 & 27.75 & 6.59 & 18.68 & 9.23 & 33.27 & 16.21 & 37.57 & 10.03 & 4.21 \\
\hline 20 & 4.28 & 4.52 & 4.64 & 4.11 & 3.66 & 22.87 & 27.44 & 25.34 & 18.82 & 6.65 & 13.28 & 24.91 & 8.49 & 12.64 & 4.36 \\
\hline K1 & 4.14 & 4.10 & & 4.30 & 4.12 & 26.85 & 15.04 & & 23.1 & 5.62 & 18.75 & 13.29 & & 2.51 & 5.02 \\
\hline $\mathrm{K} 2$ & 3.60 & 3.51 & 3.76 & 3.80 & 3.98 & 14.48 & 15.15 & 20.46 & 15.15 & 6.66 & 25.20 & 11.25 & 3.18 & 8.52 & 4.62 \\
\hline K3 & 4.00 & 3.91 & 4.27 & 4.22 & 4.46 & 14.10 & 14.85 & 4.87 & 21.01 & 4.48 & 19.14 & 15.16 & 14.27 & 11.86 & 7.34 \\
\hline K4 & 4.16 & & 3.82 & 4.61 & 4.23 & 23.07 & & 13.19 & 22.3 & 9.56 & 24.05 & & 16.26 & 2.11 & 3.23 \\
\hline
\end{tabular}


with sparse data. The following sections briefly describe FBN and how it was used in this study.

\subsubsection{Fuzzy Boolean Nets}

Natural or biological neural systems have a certain number of features that lead to their learning capability when exposed to sets of experiments from the real world. They also have the capability to use newly gained knowledge to perform approximate reasoning. Fuzzy Boolean Nets (FBN) (Tomé, 1998a, 1998b) were developed with the goal of exhibiting this kind of behavior. FBN can be considered a neural fuzzy model (Lin and Lee, 1996) where the fuzziness is an inherent emerging property, while in other known models, fuzziness is either artificially introduced on neural nets or neural components are inserted on the fuzzy systems (Pedrycz and Gomide, 2007).

In FBN, neurons are grouped into areas. Each area can be associated with a given variable or concept. Meshes of weightless connections between antecedent neuron outputs and consequent neuron inputs are used to perform If...Then inference between areas. Neurons are binary, and the meshes are formed by individual random connections (just likein nature). Each neuron contains minputs for each antecedent area, and a upper limit of $(m+1)^{N}$ internal unitary memories, where $N$ is the number of antecedents. This number corresponds to the maximum granularity (Pedrycz and Gomide, 2007), and can be reduced. It is considered that each neuron's internal unitary memory can also have a third state with the "not taught" meaning. As in nature, the model is robust in the sense that it is immune to individual neuron or connection errors (which is not the case of other models, such as the classic artificial neural net) and presents good generalization capabilities.

The "value" of each concept, when stimulated, is given by the activation ratio of its associated area (which is given by the relation between active and output " 1 " - neurons and the total number of neurons).

Later developments use the "non-taught" state of FF, and an additional Emotional Layer (Tomé and Carvalho, 2004) to deal with validation and solve dilemmas and conflicting information.

2.4.1.1. Inference. Inference proceeds in the following way: each consequent neuron samples each of the antecedent areas using its $m$ inputs. Note that $m$ is always much smaller than the number of neurons per area. For rules with $N$ antecedents and a single consequent, each neuron has $N * m$ inputs. In this particular case, rules have a single antecedent; therefore, each consequent neuron will have $m$ inputs. The single operation carried out by each neuron is the combinatorial count of the number of activated inputs from every antecedent (in the single antecedent case, this operation is reduced to counting the active inputs). Neurons have a unitary memory (FF) for each possible count combination, and its value will be compared with the corresponding sampled value. If the $\mathrm{FF}$ corresponding to the sampled value of all antecedents contains a ' 1 ', then the neuron output will be ' 1 ' (the neuron will be - or remain - activated); if the FF is ' 0 ', then the neuron output will be ' 0 '. These operations can all be performed with classic Boolean AND/OR. As a result of the inference process (which is parallel), each neuron will assume a binary value, and the inference result will be given by the neural activation ratio in the consequent area.

It has been shown (Tomé, 1998a) that, from these neuron micro operations, emerge a macro qualitative reasoning capability involving the concepts (fuzzy variables) (Pedrycz and Gomide, 2007), which can be expressed as rules of type:

"IF Antecedent1 is A1 AND Antecedent2 is A2 AND ...THEN Consequent is $\mathrm{Ci}^{\prime \prime}$, where Antecedent 1 , Antecedent2,.., Antecedent2 are fuzzy variables and A1, A2; ..., Ci are linguistic terms with binomial membership functions (such as, "small", "high", etc.).
2.4.1.2. Learning. Learning is performed by exposing the net to experiments and by modifying the internal binary memories of each consequent neuron according to the activation of the $m$ inputs (per antecedent) and the state of that consequent neuron. Each experiment will set or reset the individual neuron's binary memories. Since FBN operations are based on random input samples for each neuron, learning (and inference) is a probabilistic process. For each experiment, a different input configuration (defined by the input areas specific samples) is presented to each and every one of the consequent neurons, and addresses one and only one of the internal binary memories of each individual neuron. Updating of each binary memory value depends on its selection (or not) and on the logic value of the consequent neuron. This may be considered a Hebbian (Hebb, 1949) learning process if pre and post-synaptic activities are given by the activation ratios. A more detailed description of the learning process and proof that the network converges to a taught rule can be found in Tomé, 1998a.

It has also been shown (Tomé and Carvalho, 2002) that a FBN is capable of learning a set of different rules without cross-influence between different rules and that the number of distinct rules that the system can effectively distinguish (in terms of different consequent terms) increases with the square root of the number $m$.

Finally, it has been shown that a FBN is a Universal Approximator (Tomé, 1998a) since it theoretically implements a Parzen Window estimator (Parzen, 1962). This means that these networks are capable of implementing any possible multi-input single-output function of the type: $[0,1]^{n} \mathrm{x}[0,1]$.

These results provide the theoretical background to establish the capability of these simple binary networks to perform qualitative reasoning and effective learning based on real experiments.

\subsubsection{Extracting information from prescribed fire effects in soil properties data}

FBN were used to try to extract a complete linguistic relation that models how the analyzed parameters change after the prescribed fire. The linguistic rules describing the relation have the form of the following example:

\section{"If Organic Matter is Low before prescribed fire, then it becomes Medium/High after d days"}

In order to use FBN to extract information on prescribed fire effects in soil properties, the antecedent and consequent linguistic term set of the variables involved in the analysis must be properly defined a-priori: even knowing that FBN have the capability of automatically extracting linguistic membership functions from raw quantitative data, the scarcity of available data does not allows us to obtain an acceptable granularity. This restriction might be eliminated as more data become available, and the results compared with the present ones. Therefore, experts were contacted to establish linguistic terms to characterize the range of values in each analyzed parameter. Table 2 shows an example of the proposed range for the parameters $\mathrm{pH}$, Iron content and Organic Matter, and Fig. 4 shows an example of the membership functions used for $\mathrm{pH}$ linguistic terms.

All available raw data, which resulted from crisp uncertain measurements and/or observations, are used to train the FBN. Since the data set is not enough to provide a complete rule base, i.e., a rule for every available linguistic term, then the rule base must be necessarily completed before it can be used. FBN mesh based structure gives them a good generalization capability. Even small sized FBN can automatically interpolate values from large areas where training data was missing. For example, a FBN with 128 neurons per area, each with 25 inputs, can properly cover $20 \%$ of the input area for each provided crisp input results (Carvalho and Tomé, 2007). This is a theoretical limit, and in practice it is possible to obtain even better coverage. When using the proposed FBN settings it is possible to obtain valid 
Table 2

Linguistic characterization.

\begin{tabular}{llllc}
\hline $\mathrm{pH}$ & $\begin{array}{l}\text { PH value } \\
\text { range }\end{array}$ & $\begin{array}{l}\text { Soil moisture, } \\
\text { organic matter }\end{array}$ & $\begin{array}{l}\text { Soil moisture } \\
\text { value range (\%) }\end{array}$ & $\begin{array}{l}\text { Organic matter } \\
\text { value range (\%) }\end{array}$ \\
\hline Very acid & $\leq 4.5$ & Inexistent & $0-4$ & $0-2$ \\
Acid & $4.6-5.5$ & Very low & $5-9$ & $3-5$ \\
Low acid & $5.6-6.5$ & Low & $10-15$ & $6-15$ \\
Neutral & $6.6-7.5$ & Medium & $16-23$ & $16-30$ \\
Low alkaline & $7.6-8.5$ & High & $24-34$ & $31-45$ \\
Alkaline & $8.6-9.5$ & Very high & $35-100$ & $46-100$ \\
\hline
\end{tabular}

complete rule bases even with gaps up to $80 \%$. This is obviously highly dependent on the nature of the problem we are dealing with, and for a gap that size, the fire effect on the analyzed component must be rather linear. In conclusion, such FBN can be used to complete any rule base for which 5 evenly spaced data points exist, obtaining a qualitative universal approximator as a result of the FBN inference. In the present case, since this work is still preliminary, the number of data points is often smaller, so it cannot be guaranteed that the rule base is complete.

The procedure is as follows:

1. For each parameter at each sample depth, use a FBN with one antecedent associated with the pre-fire data, and one consequent area for each of the post-fire available data (day 0, day 1, month 4 , month 7 , month 21). Define 128 neurons per area with 25 inputs each and use maximum granularity. Although a larger FBN could provide a finer approximation degree, these settings provide a good compromise between computer performance and results.

2a) For each available expert rule obtain the centroid of the antecedent and consequent linguistic terms $\left(x_{i}, z_{k}\right)$;

2b) For each available data point use the training data directly;

3. Use all the points and all $x_{i}, z_{k}$ as training data for the FBN. In such a FBN, twenty training epochs are sufficient to produce stable results;

4. After training completion, the FBN behaves as a qualitative approximator describing the effect of prescribed fire on the analyzed parameter in a large part of the UoD;

5. To obtain the consequent of a missing rule $\left(C_{j}\right)$, one has to feed the FBN with the centroid of the antecedent linguistic term of that rule. Since FBN are probabilistic, one should infer the FBN several times and find the average of the results to obtain $z_{j}$. The chosen consequent, $C_{j}$, will be the one where $z_{j}$ has the highest membership degree;

6. Completion is guaranteed as long as at least 5 evenly distributed and reliable data points were available, but even with 3 evenly spaced rules/ data points is possible to obtain good results (Carvalho and Tomé, 2007). Since FBN provide a way to verify the validity of a certain result (based on the ratio of taught/non

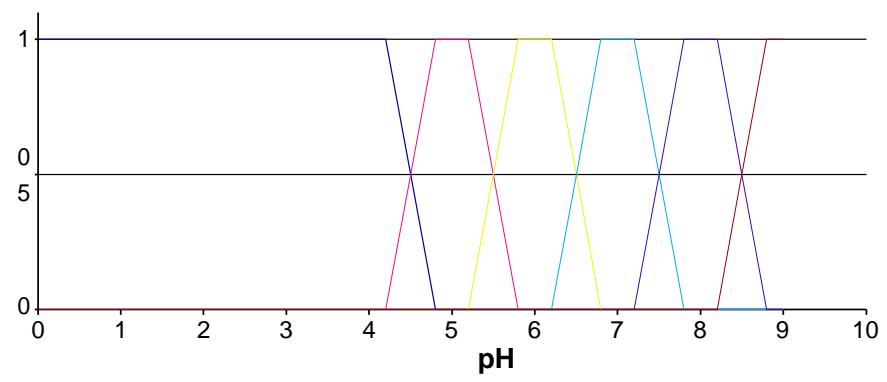

\begin{tabular}{|lll|}
\hline Very Acid & Acid & Low Acid \\
\cline { 2 - 3 } Neutral & Low Alkaline & Alkaline \\
\cline { 2 - 3 } & & Llk
\end{tabular}

Fig. 4. pH linguistic terms and membership functions. taught neurons that were used to infer the result) it is always possible to know how satisfactory the completion is.

Whenever conflicting or incongruent data exists, one must use the FBN validation mechanisms and emotional layer to minimize their influence. Therefore extra parameterization is required in this step, but the overall approach remains the same.

The outputs from the FBNetwork were also used to obtain a qualitative linguistic description of the effects of the prescribed fire in what concerns the variation of the analyzed soil properties. This was accomplished using a Mandani fuzzy rule based system (Pedrycz and Gomide, 2007) where several sets of simple fuzzy rule bases compare the pre-fire and post fire linguistic terms given by the FBN. For example:

"IF Organic Matter is Low before fire AND Organic Matter is Med after $D_{n}$ days THEN Organic Matter Increased".

\section{Results and discussion}

The available data was applied to the described FBN, and the results were compared to the control points' data. Contrary to the results obtained when the procedure was applied in the Gramelas region (Meira-Castro et al., 2010), the FBN was not able to extract any relevant conclusion regarding the prescribed fire effects on the analyzed soil properties after the 21 -month period, despite having enough data to cover a wide range of inputs (except for the case of $\mathrm{pH}$ ). The FBN validation mechanisms, when associated with the control points, indicated that one cannot conclude anything regarding the evolution of the analyzed parameters, and that the observed changes are not related with the prescribed fire action.

Changes in the available $\mathrm{pH}$ data range do not have a coherent behavior that can be qualitatively described or associated with the prescribed fire. Points with similar initial $\mathrm{pH}$ value end up with rather different $\mathrm{pH}$ after the 21-month period, some more acidic, other less acidic. Hence no conclusions or qualitative description is possible.

Changes in soil moisture and in organic matter contents have a more identifiable qualitative behavior through time, but the behavior is similar to the one occurring in the control points that were not submitted to the prescribed fire. Probably the behavior is associated with other conditions, such as rainy weather in the case of soil moisture, or a conjunction of rain and warm weather in the case of organic contents. Like in $\mathrm{pH}$, one can state that the prescribed fire does not have a relevant impact in soil moisture and in organic matter after the 21-month period.

The inclusion of meteorological parameters during soil monitoring should be considered in a future larger study to support the above discussion.

\section{Conclusions}

Prescribed fires are used in Portugal as a forest fuel mass management technique in order to reduce the intensity and severity of wildfires in the Summerseason.

Although there are several scientific works available on the impact of fires in forest soils, there is still an insufficient amount of scientific information related with the northwestern forests of Portugal, in particular in what concerns prescribed fires effects. In addition, there is no information about the adequacy of this technique in an environment already severely damaged by recurrent wildfires.

Fuzzy Boolean Nets (FBN) were used to qualitatively evaluate the alteration in soils parameters subject to a prescribed fire when compared with adjacent spots where: i) no fire occurrence was registered since 1998; ii) fire occurrence was registered in 2008; and iii) 
vegetation pruning by mechanical cut was done in Spring, six months prior to the prescribed fire event.

Results suggest that in the particular case of the studied site, Anjos, the observed soil properties alterations cannot be related with the prescribed fire.

\section{Acknowledgments}

The authors want to thank the colleagues from the AFN Portuguese Forestry Services, who provided the operational facilities and some data need to illustrate the present study. They are also grateful to all the students involved in both field and laboratory work.

This work was partially supported by FCT (INESC-ID multiannual funding) through the PIDDAC Program funds.

\section{References}

AFN, 2006. Plano Nacional de Defesa da Floresta Contra Incêndios (PNDFCI). Diário da República n.102, I-B Série, 26 de Maio 2006, pp. 3511-3559.

Agroconsultores and Geometral, 1995. Carta dos Solos e Carta de Aptidão da Terra de Entre Douro e Minho - Memórias.

Arianoutsou, M., 2006. Wildland Fires Impacts: A State of the Art. EUFIRELAB - Deliverable D-04-12.

Bento-Gonçalves, A., 2006. Geografia dos Incêndios em Espaços Silvestres de Montanha - o caso da Serra da Cabreira. PhD thesis. Universidade do Minho, Braga, Portugal.

Bitner, K., Gallaher, B., Mullen, K., 2001. Review of Wildfire Effects on Chemical Water Quality. Los Alamos National Laboratory edition.

Botelho, H.S., Rego, F.C., Ryan, K.C., 1998. Tree mortality models for Pinus pinaster of Northern Portugal. Proceedings of the 13th Conference on Fire and Forest Meteorology. International Association of Wildland Fire, pp. 235-240.

Botelho, H., 2000. Fire Torch Deliverable E1 - State of the art on prescribed burning ecological effects: review of the existing research results on prescribed fire effects on Mediterranean ecosystems. E1a.Effects on soil; E1b.Effects on fauna; E1c.Effect onvegetation; E1d.Effects on trees. Fire Torch Project Contract No ENV4-CT98-0715.

Campos, A., 2004. Uma proposta de avaliação ecológica da Serra da Cabreira. Msc thesis. Universidade do Minho, Braga, Portugal.

Carvalho, J.P., Tomé, J.A., 2007. Qualitative optimization of fuzzy causal rule bases using fuzzy Boolean Nets. Fuzzy Sets and Systems 158 (17), 1931-1946 Elsevier.

Carvalho, A., Flannigan, M.D., Logan, K., Miranda, A.I., Borrego, C., 2008. Fire activity in Portugal and its relationship to weather and the Canadian Fire Weather Index System. International Journal of Wildland Fire 2008 (17), 328-338.

Catry, F.X., Rego, F., Moreira, F., Fernades, P.M., Pausas, J.G., 2010. Post-fire tree mortality in mixed forests of central Portugal. Forest Ecology and Management 206, 1184-1192.

Cerdà, A., Doerr, S., 2005. The influence of vegetation recovery on soil hydrology and erodibility following fire: an eleven year investigation. International Journal of Wildland Fire 14, 423-437.

Certini, G., 2005. Effects of fire on properties of forest soils: a review. Oecologia 143, $1-10$.

Coelho, C.O.A., Ferreira, A.J.D., Boulet, A.K., Keizer, J.J., 2004. Overland flow generation processes, erosion yields and solute loss following different intensity fires. Quarterly Journal of Engineering Geology and Hydrology 37, 233-240.

DeBano, L.F., 2000. The role of fire and soil heating on water repellency in wildland environments: a review. Journal of Hydrology 231-232, 195-206.

Devi-Vareta, N., 1993. A floresta no espaço e no tempo em Portugal : a arborização da Serra da Cabreira 1919-1975. PhD Thesis. Universidade do Porto, Portugal.

DRAEDM-Agroconsultores \& Geometral, 1995. Soil and possible land use on Entre Douro and Minho region-Carta de solos e carta de aptidao da terra do Entre Douro e Minho. Escala 1: 100000.

Durão, R.M., Pereira, M.J., Branquinho, C., Soares, A., 2010. Assessing spatial uncertainty of the Portuguese fire risk through direct sequential simulation. Ecological Modelling 221 (1), 27-33.

EUFIRELAB, 2006. Methods to Study Fire Impacts on Plants (forest stands, shrubs, herbaceous taxa), Soil and Fauna.

Ferreira, A.J.D., Coelho, C.O.A., Walsh, R.P.D., Shakesby, R.A., Ceballos, A., Doerr, S.H., 2000. Hydrological implications of soil water-repellency in Eucalyptus globulus forests, north-central Portugal. Journal of Hydrology 231-232, 165-177.

Ferreira-Leite, F., Bento-Gonçalves, A., Vieira, A., 2011. The recurrence interval of forest fires in Cabeça da Vaca (Cabreira Mountain - northwest of Portugal). Environmental Research 111,215-221.

Gimeno-Garcia, E., Andreu, V., Rubio, J.L., 2000. Changes in organic matter, nitrogen, phosphorus and cations in soil as a result of fire and water erosion in a Mediterranean landscape. European Journal of Soil Science 51, 201-210.

González-Pérez, J.A., González-Vila, F.J., Almendros, G., Knicker, H., 2004. The effect of fire on soil organic matter - a review. Environment International 30, 855870 .

Hebb, D., 1949. The Organization of Behaviour: A Neuropsychological Theory. John Wiley \& Sons.

IPQ - Instituto Português da Qualidade, 2009. Norma Portuguesa: Sistemas de gestão dos crítérios pan-europeus para a gestão florestal sustentável.
ISO 10381-1, 2002. Soil Quality-Sampling - Guidance on the Design of Sampling Programmes.

ISO 10381-2, 2002. Soil Quality-Sampling - Guidance on Sampling Techniques.

ISO 11464, 2006. Soil Quality - Pretreatment of Samples for Physico-Chemical Analysis.

ISO 11465, 1993. Soil Quality - Determination of Dry Matter and Water Content on a Mass Basis - Gravimetric Method.

ISO 10694, 1995. Soil Quality - Determination of Organic and Total Carbon after Dry Combustion (Elementary Analysis).

Kutiel, P., Inbar, M., 1993. Fire impacts on soil nutrients and soil erosion in a Mediterranean pine forest plantation. Catena 20, 129-139.

Lin, C.-T., Lee, C.S.G., 1996. Neural Fuzzy Systems: A Neuro-Fuzzy Synergism to Intelligent Systems. Prentice-Hall, pp. 301-309.

MADRP - Ministério da Agricultura, do Desenvolvimento Rural e das Pescas, 2007. Portaria n.o 755/2007 de 29 de Junho. Diário da República, 1.a série - N.o 124 - 29 de Junho de 2007, p. 4163

Mayor, A.G., Bautista, S., Llovet, J., Bellot, J., 2007. Post-fire hydrological and erosional responses of a Mediterranean landscape: seven years of catchment-scale dynamics. Catena 71, 68-75.

Meira-Castro, A.C., Meixedo, J.P Gois, J, Ribeiro, S., Delerue-Matos, C.M., Albergaria, J.T., Vivas, A., 2010. Impact of prescribed fire on the chemical properties of soil. In: Viegas, D.X. (Ed.), VI International Conference on Forest Fire Research.

Meira-Castro, A.C., Carvalho, J.P., Ribeiro, S., 2011. Prescribed burning impact on forest soil properties - a Fuzzy Boolean Nets approach. Environmental Research 111, 199-204.

Miranda, A.I., Coutinho, M., Borrego, C., 1994. Forest fire emissions in Portugal: a contribution to global warming? Environmental Pollution 83, 121-123.

Moreira, F., Delgado, A., Ferreira, S., Borralho, R., Oliveira, N., Inácio, M., Sande-Silva, J., Rego, F., 2003. Effects of prescribed fire on vegetation structure and breeding birds in young Pinus pinaster stands of northern Portugal. Forest Ecology and Management $184,225-237$

Neary, D.G., Klopatek, C.C., DeBano, L.F., Ffolliott, P.F., 1999. Fire effects on belowground sustainability: a review and synthesis. Forest Ecology and Management $122,51-71$

Neary, D.G., Ryan, Kevin, DeBano, C., Leonard, F., 2008. Wildland fire in ecosystems: effects of fire on soils and water. General Technical Report RMRS-GTR-42-vol.4. USDA, Forest Service. Rocky Mountain Research Station.

Parzen, E., 1962. On estimation of a probability density function and mode. Annals of Mathematical Statistics 33, 1065-1072.

Pausas, J.G., Vallejo, V.R., 1999. The role of fire in European Mediterranean Ecosystems Mediterranean basin, chap.2, pp. 3-16. Springer-Verlag.

Pedrycz, W., Gomide, F., 2007. Fuzzy Systems Engineering, Toward Human-Centric Computing. John Wiley \& Sons, Inc, Hoboken, New Jersey.

Pausas, J.G., Llovet, J., Rodrigo, A., Vallejo, R., 2008. Are wildfires a disaster in the Mediterranean basin? - A review. International Journal of Wildland Fire 17, 713723

PCM, 2006. medidas e acções a desenvolver no âmbito do Sistema Nacional de Defesa da Floresta contra Incêndios. Dec-Lein ${ }^{\circ} 124 / 2006$. Diário da Républica n ${ }^{\circ} 123$ de 28 de Junho de 2006- I Série-A, pp. 4586-4599.

RCM - Resolução do Conselho de Ministros n65, 2006. Plano Nacional de defesa da Floresta contra Incêndios (PNDFCI). Diário da República nº102 de 26 de Maio de 2006 - I Série-B, pp. 3511-3559.

Ribeiro, M.A., Martins, H.C., Almeida, A., Noronha, F., 2000. Notícia explicativa da carta geológica de Portugal, Folha 6-C.

Ribeiro, S., Delerue-Matos, C.M., Meira-Castro, A.C., Albergaria, J.T., 2010. Study on the changes of soil chemical characteristics as result of prescribed fire. III Meeting of young researchers at UP, p. 265.

Serviços Geológicos de Portugal, 1961. Carta Geológica de Portugal, Notícia explicativa de Caminha.

Shakesby, R.A., Boakes, D.J., Coelho, C., Gonçalves, A.J.B., Walsh, R.P.D., 1996. Limiting the soil degradational impacts of wildfire in pine and eucalyptus forests in Portugal: a comparison of alternative post-fire management practices. Applied Geography 16, 337-355.

Shakesby, R.A., Doerr, S.H., 2006. Wildfire as a hydrological and geomorphological agent. Earth-Science Reviews 74, 269-307.

Shakesby, R.A., 2011. Post-wildfire soil erosion in the Mediterranean: review and future research directions. Earth-Science Reviews 105 (3-4), 71-100.

Silva, J.S., Rego, F.C., Mazzoleni, S., 2006. Soil water dynamics after fire in a Portuguese shrubland. International Journal of Wildland Fire 15, 99-111.

Tomé, J.A., 1998a. Counting Boolean networks are universal approximators. Proceedings of the 1998 Conference of NAFIPS, Florida, USA, pp. 212-216.

Tomé, J.A., 1998b. Neural activation ratio based fuzzy reasoning. Proceedings of the IEEE World Congress on Computational Intelligence, Anchorage. Alaska, U.S.A. , pp. 1217-1222.

Tomé, J.A., Carvalho, J.P., 2002. Rule capacity in fuzzy Boolean networks. Proceedings of the 21st International Conference of the North American Fuzzy Information Processing Society, NAFIPS2002, New Orleans, pp. 124-128.

Tomé, J.A., Carvalho, J.P., 2004. Decision validation and emotional layers on fuzzy Boolean networks. Proceedings of the 23rd International Conference of the North American Fuzzy Information Processing Society, NAFIPS2004, Banff, Canada, pp. 136-139.

Trigo, R.M., Pereira, J.M.C., Pereira, M.G., Mota, B., Calado, T.J., Câmara, C.C., Espirito Santo, F., 2006. Atmospheric conditions associated with the exceptional fire season of 2003 in Portugal. International Journal of Climatology 26, 1741-1757.

Úbeda, X., Lorca, M., Outeiro, L.R., Bernia, S., Castellnou, M., 2005. Effects of prescribed fire on soil quality in Mediterranean grassland (Prades Mountains, north-east Spain). International Journal of Wildland Fire 14, 379-384. 
Vega, J.A., Fernández, C., Fonturbel, T., 2005. Runoff and soil erosion after prescribed burning in gorse shrubland in Galicia (NW Spain). Land Degradation \& Development $16,37-51$.

Viegas, D.X., 2006. Forest fires in Portugal in 2005 - an overview. International Forest Fire News (IFFN) 34, 22-30
Vivas, A., 2008. Plano Operacional de Queima - Execução. PLANO DE FOGO CONTROLADO N. ${ }^{\circ}:$ QQQ/01/58/2008.

Zozaya, E.L., Brotons, L., Vallecillo, S., 2011. Bird community responses to vegetation heterogeneity following non-direct regeneration of Mediterranean forests after fire. Ardea 99, 73-84. 